\title{
Methodological Approach to Formation of Indicators of Labor Productivity Growth as a Means of Increasing Competitiveness of Enterprises
}

\author{
Anatoly Andreevich Rudychev ${ }^{1}$, Svetlana Petrovna Gavrilovskaya ${ }^{1}$, Elena Alexsandrovna Nikitina ${ }^{1}$, Lyudmila \\ Vitalievna Bugaenko ${ }^{1} \&$ Alexander Valeryevich Borachuk ${ }^{1}$ \\ ${ }^{1}$ Belgorod state technological University V. G. Shukhov, Russian Federation \\ Correspondence: Svetlana Petrovna Gavrilovskaya, Kostyukova str., 46, Belgorod, 308012, Russian Federation. \\ E-mail: sgavril@inbox.ru
}

Received: February 12, 2015 Accepted: March 30, 2015 Online Published: July 30, 2015

doi:10.5539/ass.v11n19p22 URL: http://dx.doi.org/10.5539/ass.v11n19p22

\begin{abstract}
Increasing competitiveness of enterprises involves the introduction of new technologies in production and management focused on continuous monitoring of labor productivity as well as identifying indicators of its growth. Forming groups of factors and evaluation of their impact on labor productivity allows us to find reserves of its growth. The aim of the study was to develop a methodological approach to provide reasonable set of indicators of labor productivity growth, aimed at increasing competitiveness of enterprises. Developed tools make it possible to calculate and substantiate the growth indicators variation with regard to the predicted value of labor productivity. This methodological approach can be used to identify directions of growth of enterprise competitiveness.
\end{abstract}

Keywords: competitiveness, labor productivity, indicators of labor productivity growth, variation of growth indicators, forecasting, regression and correlation analysis

\section{Introduction}

Issues on production modernization and increasing competitiveness of the Russian economy as a whole, and individual enterprises in particular, have recently become quite popular. These issues are especially notable right now, because it is during the crisis that the notion of competitiveness of the economy, which depends primarily on the efficient use of available resources and high labor productivity, becomes the most evident (Chizhova, 2010).

Enterprises of the country which are competitive in the global market are the backbone of the effective economy. High rates of scientific-and-technological advance, the inflow of investment aimed at the development of production with a view to the development and improvement of technological processes leading to increased productivity, lower costs, turnover and liquidity growth, introduction of innovations, development of automated information technologies - these are only some processes that increase competition between producers in the market (Demura, 2013, pp. 357-364). In current situation the management of any company should be able not only to capture the trends in the development of the target market, but also to respond adequately to changes in the foreign market for the successful development. In our opinion, today the enterprise should have the competitiveness management system, clearly responding to the emerging trends in economic development.

First it is necessary to identify those competitive factors of the enterprise to which it may have the given impact. Of the variety of factors, affecting the dynamics of enterprise development, internal remain the most important. The internal factors include (Tsarevetal, 2008):

a) the most effective resource suppliers;

b) share of the captured target market (segment);

c) number of competitors in the target market (segment);

d) extent of outsourcing;

e) development of the distribution (dealer) network; 
f) management quality (proficiency level of managerial staff);

g) aggregate evaluation of personnel capacity;

h) degree of protection of confidential information (information system security);

i) extent of use of modern information technologies;

j) Internet usage to sell products;

k) focus on the economy based on knowledge management;

1) extent of use of achievements of scientific-and-technological advance;

$\mathrm{m}$ ) the life cycle of the target market (a market in which the enterprise operates);

n) reputation (goodwill) of the enterprise;

o) improvement of the organizational and production structure;

p) high labor productivity;

q) staff motivation to improve the quality of goods;

r) competitive status (the basic premise of the enterprise to achieve a certain level of competitive advantage, that is the main objective of competition in the market);

s) the most significant strategic competitive advantages;

t) effective competitive strategy;

u) timeliness of restructuring;

v) management system quality;

w) value of the enterprise (business), reflecting its investment attractiveness.

The whole range of factors that determine the level of competitiveness cannot be considered within the framework of a single work.

In the proposed study we would like to focus on the connection between productivity and the level of the enterprise competitiveness.

In the current context the connection between productivity and competitiveness is becoming more evident. Labor productivity determines the competitiveness of the economy. In this respect it is interesting to study labor productivity not only regarding economy as a whole but also at the branch level, examining the cut of individual enterprises forming production structure of leading branches of the regional economy (Sultanova \& Burganov, 2012, pp. 203-207). The problem of the low level of competitiveness in the country is complemented by the level of funding for research and development insufficient for normal development of enterprises in the innovation economy. Attempts to create the country's advanced industrial production are doomed to fail due to lack of non-borrowed competitive technologies. It is necessary to give new impetus to the financing of the organizational and economic activity of scientific, engineering and design organizations, inventive activity (Podsumkova, 2012, pp. 43-46). Experience in various countries suggests that only an increase in labor productivity at the enterprise makes it possible to maintain the competitiveness of the economy as a whole. And the money that is spent on the search for reserves of labor productivity growth, their implementation subsequently pays off many times by decrease of both production and non-production costs, and as a result leads to the increase in revenue, profit and profitability, more efficient use of production capacity, improvement of the organizational structure, success in the competitive market struggle (Hoskissonetal, 2012; Mehri, 2012, pp. 7-10).

Today there remains the problem of the common theoretical approach as to the essence of labor productivity and the formation of growth factors. This leads to ambiguity of evaluation and measurement of the productivity level as well as the indicators, criteria, conditions and reserves of its increase. Accordingly, the construction of the system capable of managing productivity should be based on a thorough analysis of the notion of labor productivity in terms of objectives of the study, record keeping and selection of key performance indicators, conditions and reserves of its growth for their further implementation (Rudychev \& Novoyatlev, 2012, pp. 246-252; Toymentseva, 2012, pp. 64-69).

In our opinion, the problem of detecting the interrelation of the most important factors affecting the labor productivity and their most rational change in order to achieve the desired level of productivity remains relevant. The most significant internal factors of the enterprise that typically affect the labor productivity are shown in 
Table 1 (Rudychev et al., 2013, pp. 137-140).

Table 1. Factors affecting the labor productivity growth

\begin{tabular}{|c|c|}
\hline Factors & Events that determine labor productivity growth \\
\hline $\begin{array}{l}\text { Product portfolio: current and new } \\
\text { products }\end{array}$ & $\begin{array}{l}\text { regular portfolio optimization taking into account changes in the demand } \\
\text { structure and limitations in raw materials } \\
\text { expansion of the product range } \\
\text { state support for the development of new technologies and innovative } \\
\text { equipment }\end{array}$ \\
\hline Marketing and distribution & $\begin{array}{l}\text { regular analysis of the products market of its segments } \\
\text { outlined strategies in the field of branding and promotion of new products } \\
\text { pricing policy }\end{array}$ \\
\hline Personnel & $\begin{array}{l}\text { personnel development } \\
\text { optimization of working hours loss connected with the inefficient use of } \\
\text { labor }\end{array}$ \\
\hline Raw materials and supplies & $\begin{array}{l}\text { efficient use of raw materials and various components } \\
\text { observance of technological and production standards } \\
\text { amplification of the incoming quality inspection of raw materials and } \\
\text { components }\end{array}$ \\
\hline $\begin{array}{l}\text { Management and organization of } \\
\text { production processes }\end{array}$ & $\begin{array}{l}\text { effective system of seamless planning } \\
\text { effective system of operational planning } \\
\text { organization of internal logistics in the production units } \\
\text { balanced record keeping system of production processes } \\
\text { effective system of finished product quality control }\end{array}$ \\
\hline Equipment and assets & $\begin{array}{l}\text { equipment modernization } \\
\text { optimization of the system of scheduled and emergency repair of equipment }\end{array}$ \\
\hline
\end{tabular}

\section{Methodology}

As part of the development of tools and methods of labor productivity management the methodological approach in decision-making on labor productivity management on the industrial enterprise was introduced; it takes into account varying degrees of influence of productivity factors and makes it possible to evaluate the potentially optimal ratio of changes needed to achieve a given value of both the growth of labor productivity indicator and the increase of competitiveness of the enterprise as a whole.

It is well known that the main factors affecting the labor productivity are material and technical (relating to the technical level of production, improvement of technologies, equipment, materials in use), organizational (characterizing the organization of labor, production and management), socioeconomic (relating to the human component of production - qualification of employees, their motivation and job satisfaction, improvement of working conditions) (Smirnova, 2014, pp. 166-171).

All the factors and criteria characterizing them are interconnected and influence to different extent the labor productivity level. Though material and technical factors are considered to be the main ones, considering that the introduction of new equipment into the production process, technology improvement and process automation provides growth to the enterprise of such statistical indicators as capital-labor ratio and power available per employee, improves the implementation of fixed assets, increases the rate of their renewal, reduces the coefficient of wear (Krasnopevtseva, 2013, pp. 80-86).

The set of indicators is individual for each enterprise and the choice of those that can provide a significant increase in productivity usually happens intuitively. Grounded choice of indicators can be carried out using correlation analysis. Indicators having high pair correlation coefficients with labor productivity are used for further investigations.

The proposed methodological approach has the versatility and broad area of application at the industrial enterprises at low material and labor costs, allows us to solve issues on labor productivity management taking 
into account the estimated degree of factors influence. This makes it possible to forecast the necessary value change of each criterion for a given target value of labor productivity growth (Rahman \& Idris, 2000; Roberta et al., 2005; Buraeva, 2013, pp. 38-48).

Defining aim of the proposed approach of evaluating reserves of labor productivity growth in order to increase the enterprise competitiveness is to create groups of factors that determine the productivity variation, calculate their growth rates, as well as recalculate the main indicators of the enterprise, taking into account the estimated percent of the factors growth (Nikitina, 2014).

Figure 1 shows the integrated scheme of methodology implementation, which clearly reflects the main stages and steps on evaluation of reserves of productivity growth as a means of increasing the competitiveness of enterprises, and also allows us to substantiate the growth percentage of the individual values of factors influencing the productivity variation. Microsoft Excel is the means of implementation of the proposed methodological approach. This package is selected as the most comprehensive tool that makes it possible to implement all the steps of methodology, that has a wide range of versatile add-ons for evaluation of pair correlation coefficients, regression coefficients, parameters of the constructed models adequacy, as well as analysis tool "what if ..." - Goal Seek.

Now we will concentrate on the main features of the proposed methodological approach. Three main stages can be distinguished in the calculations. At the first stage the identification, collection and primary processing of data on the enterprise for the analyzed period take place (in our opinion, the analyzed period must include at least three years).It is followed by the formation of the sample of observations, the choice of economic factors $\left(x_{j}, j=\right.$ $1,2, \ldots, \mathrm{m})$, which have the most significant effect on the variation of productivity, that is having high pair correlation coefficients $\left(r_{\mathrm{yxj}}, \mathrm{j}=1,2, \ldots, \mathrm{m}\right)$.

At this stage the indicators that have a close relationship with each other should be excluded, as in the subsequent calculations multicollinear factors will lead to biased estimates of regression parameters.

For the obtained group of factors one should determine the type of individual functional dependencies between indicators and labor productivity $(y=f(x j)$, where $j=1,2, \ldots, m$ - number of factor, that significantly affects the dependent variable for the generated sample of observations). As a rule, linear $(y=a+b x)$, non-linear $(y=a+$ $\mathrm{bx}^{2}$ and $\left.\mathrm{y}=\mathrm{a}+\mathrm{bx}^{1 / 2}\right)$ and logarithmic $(\mathrm{y}=\mathrm{a}+\mathrm{b} \cdot \ln \mathrm{x})$ dependencies are the most reliable between productivity and material and technical factors. Then taking into account the estimated pair dependency, the parameters of multiple regression should be estimated. Further one must evaluate the adequacy of the model according to the criteria of Fisher and Student (Kremer, 2007).If the multiple model is inadequate, it is necessary to go back to the original data, perhaps form a new sample of observations, having updated it, form a group of factors and analyze the new multiple dependency. If the evaluated model parameters are reliable, one should carry out the transition to the second stage of the methodology. Namely it is necessary to perform ranking of factors by degree of their influence on the dependent variable. Criterion which is used for ranking of model factors is the value of calculated standardized regression coefficient (Danilov, 2006).

Upon completion of the stage, a general table of parameters of multiple regression is formed (Table. 2), including the value of the regression coefficients $\left(\mathrm{K}_{\mathrm{i}}\right)$, the standardized regression coefficients $\left(\mathrm{K}_{\mathrm{i}}{ }^{\prime}\right)$, the rank of the factors included in the model $\left(\mathrm{p}_{\mathrm{i}}\right)$, the multiple regression equation $(\mathrm{Y}=)$, and also the parameters of the model adequacy $\left(\mathrm{R}^{2}\right.$, F-statistic).

Table 2. Evaluation of regression parameters

\begin{tabular}{llllllll}
\hline & $\mathbf{x}_{\mathbf{1}}$ & $\mathbf{x}_{\mathbf{2}}$ & $\mathbf{x}_{\mathbf{3}}$ & $\cdots$ & $\mathbf{x}_{\mathbf{n}}$ & $\mathbf{y}$ & $\mathbf{c}$ \\
\hline $\mathbf{K}_{\mathbf{i}}$ & $\mathrm{b}_{1}$ & $\mathrm{~b}_{2}$ & $\mathrm{~b}_{3}$ & $\cdots$ & $\mathrm{b}_{\mathrm{n}}$ & & $\mathrm{b}_{0}$ \\
$\mathbf{K}_{\mathbf{i}}{ }^{\prime}$ & $\mathrm{b}_{1}{ }^{\prime}$ & $\mathrm{b}_{2}{ }^{\prime}$ & $\mathrm{b}_{3}{ }^{\prime}$ & $\ldots$ & $\mathrm{b}_{\mathrm{n}}{ }^{\prime}$ & & \\
Factor rank & $\mathrm{p}_{1}$ & $\mathrm{p}_{2}$ & $\mathrm{p}_{3}$ & $\cdots$ & $\mathrm{p}_{\mathrm{n}}$ & & \\
$\mathbf{Y}=$ & $\mathrm{y}=\mathrm{f}\left(\mathrm{x}_{1}, \mathrm{x}_{2}, \ldots, \mathrm{x}_{\mathrm{n}}\right)$ & & & & \\
$\mathbf{R}^{\mathbf{2}}$ & $\mathrm{R}^{2}$ & & & & & \\
$\mathbf{F}$-statistic & $\mathrm{F}$ & & & & & \\
\hline
\end{tabular}

The calculation of the performance attribute taking into account selection of growth percentage of individual values of factors opens the next stage of the described methodology. Individual values of factors can be determined as weighted average values $\mathrm{x}_{\mathrm{i}}$ according to the sample of observations, or the values for the last 
observation period, or the values as close to the predicted ones for the future periods. Point value of labor productivity is determined using the estimated multiple dependency:

$$
y^{*}=b_{0}+b_{1} x_{1}^{*}+b_{2} x_{2}^{*}+b_{3} x_{3}^{*}+\ldots+b_{m} x_{m}^{*}
$$

where $\mathrm{y}^{*}$ - point prediction of a performance attribute, $x_{1}^{*}, x_{2}^{*}, x_{3}^{*}, \ldots, x_{m}^{*}$, the individual values of factors for the forecast.
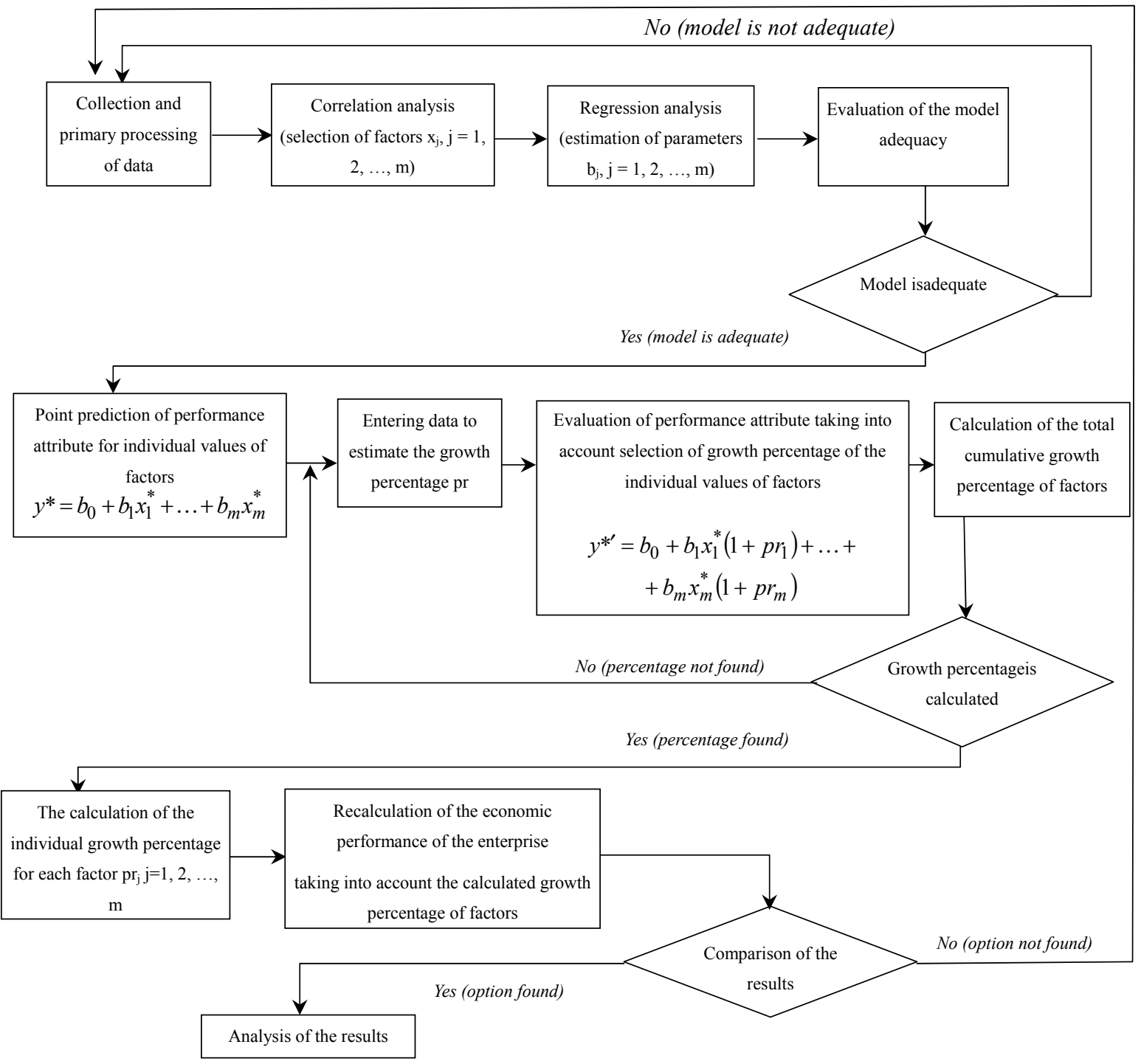

Figure 1. General scheme of methodology for evaluation of individual growth percentage of factors

Planned indicators are used to enter the growth percentage (pr) of labor productivity. Then evaluation of performance attribute value is carried out taking into account the growth of the individual values of factors, which are calculated considering ranking by the equation (1)

$$
y^{*^{\prime}}=b_{0}+b_{1} x_{1}^{\prime}+b_{2} x_{2}^{\prime}+b_{3} x_{3}^{\prime}+\ldots+b_{m} x_{m}^{\prime}
$$

where $x_{1}^{\prime}=x_{1}^{*}\left(1+p r_{1}\right), x_{2}^{\prime}=x_{2}^{*}\left(1+p r_{2}\right), \ldots, x_{m}^{\prime}=x_{m}^{*}\left(1+p r_{m}\right)$, values of factors considering the growth percentage, $\mathrm{pr}_{1}, \mathrm{pr}_{2}, \ldots, \mathrm{pr}_{\mathrm{m}}$ - growth percentage of factorsx $\mathrm{x}_{1}, \mathrm{x}_{2}, \ldots, \mathrm{x}_{\mathrm{m}}$.

And the third and final step is to recalculate the economic performance of the enterprise considering the individual projected value of factors growth, as well as the comparison and analysis of the results obtained and making recommendations to achieve the predicted values of indicators of business activity of the enterprise. All calculations are recorded in the table of recalculation of the enterprise performance (Table 3). 
Table 3. Economic indicators of business activity of the enterprise

\begin{tabular}{llll}
\hline Indicators & Observed values & Values considering forecast & Changes \\
\hline Performance attribute $(\mathrm{y})$ & $\mathrm{y}$ & $\mathrm{y}^{* \prime}$ & $\Delta \mathrm{y}$ \\
Factor 1 $\left(\mathrm{x}_{1}\right)$ & $x_{1}^{*}$ & $x_{1}^{\prime}=x_{1}^{*}\left(1+p r_{1}\right)$ & $\Delta \mathrm{x}_{1}$ \\
Factor 2 $\left(\mathrm{x}_{2}\right)$ & $x_{2}^{*}$ & $x_{2}^{\prime}=x_{2}^{*}\left(1+p r_{2}\right)$ & $\Delta \mathrm{x}_{2}$ \\
$\ldots$ & $\ldots$ & $\ldots$ & $\ldots$ \\
Factorm $\left(\mathrm{x}_{\mathrm{m}}\right)$ & $x_{m}^{*}$ & $x_{m}^{\prime}=x_{m}^{*}\left(1+p r_{m}\right)$ & $\Delta \mathrm{x}_{\mathrm{m}}$ \\
Indicator 1 & $\mathrm{pk}_{1}$ & $\mathrm{pk}_{1}{ }^{\prime}$ & $\Delta \mathrm{pk}_{1}$ \\
Indicator2 & $\mathrm{pk}_{2}$ & $\mathrm{pk}_{2}{ }^{\prime}$ & $\Delta \mathrm{pk}_{2}$ \\
$\ldots$ & $\ldots$ & $\ldots$ & $\ldots$ \\
Indicatorn & $\ldots$ & $\mathrm{pk}_{\mathrm{n}}{ }^{\prime}$ & $\Delta \mathrm{pk}_{\mathrm{n}}$ \\
\hline
\end{tabular}

In our opinion, this technique can be used to identify effectively the areas for increasing the competitiveness of enterprises through the reserves of labor productivity growth. Implementation of the proposed methodology will allow one to make grounded management decisions aimed not only at increasing productivity, but also providing cost reduction when performing inefficient and unprepared decisions and leading to increased profitability for the enterprise as a whole.

\section{Results}

Monthly data of economic and industrial character collected in the range from January 2008 to December 2013 inclusive, covering the enterprises of construction materials industry of Belgorod region, served as information base for approbation of the proposed methodology. The choice of companies for the analysis is due to their importance for the economy of the region, as well as their standard for post-Soviet economy industrial and organizational structure, that allows one to project the results to a certain extent on the CIS countries. It should be noted that the original statistical materials taken as a basis for modeling represent a qualitatively homogeneous population that characterizes the analyzed process. Quantitative sample volume is sufficient and the analyzed parameters in the aggregate have a sufficiently large range of variation. Thus, the original data comply with all the requirements (Novoyatlev, 2013, pp. 122-125).

Tables 4-5 summarizes the results of methodology approbation on the example of the enterprises of construction materials industry of Belgorod region. As a result of the correlation analysis a group of factors was identified, determining the labor productivity growth at the enterprise during the period: the share of investment costs in the aggregate cost of the enterprise (Invc), the share of wages of workers in production costs (Wc), the share of electricity consumption in production costs (Elc), the coefficient of the intensive use of the equipment (Coi), the proportion of the active part of fixed assets (Apfa).

Table 4. Quantitative evaluation of regression parameters

\begin{tabular}{|c|c|c|c|c|c|c|c|}
\hline & Inve & Wc & Elc & Coi & Apfa & & c \\
\hline $\mathbf{K}_{\mathbf{i}}$ & 30,62 & 42,41 & 881,57 & 38,83 & 5,36 & & 3,517 \\
\hline $\mathbf{K}_{\mathbf{i}}^{\prime}$ & 0,156 & 0,813 & 0,982 & 0,578 & 0,163 & & \\
\hline Factor rank & 5 & 2 & 1 & 3 & 4 & & \\
\hline $\mathbf{Y}=$ & \multicolumn{7}{|c|}{$30,62 \cdot \operatorname{Invc}+42,41 \cdot \mathrm{Wc}+881,57 \mathrm{Elc}^{1 / 2}+38,83 \mathrm{Coi}+5,36 \mathrm{Apfa}^{2}+3,517$} \\
\hline $\mathbf{R}^{2}$ & \multicolumn{7}{|c|}{0,812} \\
\hline F-statistic & \multicolumn{7}{|c|}{36,281} \\
\hline
\end{tabular}

Table 5. Results of calculation of changes of labor productivity factors

\begin{tabular}{|c|c|c|c|c|c|c|}
\hline $\begin{array}{l}\text { Labor productivity } \\
\text { growth, \% }\end{array}$ & $\begin{array}{l}\text { Aggregate growth of } \\
\text { factors, } \%\end{array}$ & $\begin{array}{l}\text { Perce } \\
\text { the } m\end{array}$ & $\begin{array}{l}\text { ange o } \\
\%\end{array}$ & or prod & & cording to \\
\hline $\operatorname{Pr}$ & Prf & Invc & $\mathrm{Wc}$ & Elc & Coi & Apfa \\
\hline 15 & 32,473 & 2,165 & 8,659 & 10,824 & 6,495 & 4,330 \\
\hline
\end{tabular}




\section{Discussion}

The results of the quantitative analysis of labor productivity, which has important advantages over the qualitative analysis such as objectivity and ability to make an accurate assessment, are frequently not comparable between different objects of study because of the uniqueness of each business entity. The proposed methodological approach to the quantitative assessment of labor productivity growth for the purpose of management of the enterprise competitiveness ensures comparability of results by groups of enterprises. At the same time to get reasonable final result it is sufficient to analyze a representative sample of observations covering and formed by a group of enterprises under consideration belonging to the given market cluster.

The results presented in Table 5 illustrate the needed value growth of each factor to achieve the target growth of labor productivity.

The growth of labor productivity of the enterprise by $15 \%$ was projected in the study. Standardized regression coefficients allowed us to rank the factors as follows: the share of electricity consumption in production costs - 1, the share of wages of workers in production costs- 2 , the coefficient of the intensive use of the equipment - 3 , the proportion of the active part of fixed assets - 4, the share of investment costs in the aggregate cost of the enterprise - 5. This ranking is quite understandable, since the enterprises of construction materials industry are energy- and material intensive. Individual values of the growth percentage of indicators were evaluated taking into account the factor rank, and the total percentage is $-32.47 \%$ (Table 5).

The results presented are adequate only for the considered enterprises of the industry within the formed sample of observations.

In the proposed methodology for formation of indicators of labor productivity growth as a means of increasing the competitiveness rationale for choosing factors included in the model requires further study. In fact today there is no successfully formulated and generally accepted concept of enterprise competitiveness; moreover there are no objective tools to obtain a numerical evaluation of the competitiveness. The composition of indicators, subject to analytical assessment, as well as methods for integrated assessment of the level of competitiveness of enterprises differs significantly. Moreover the methods used remain unknown to other enterprises. Therefore the final results of calculations on them usually do not coincide. It is also impossible to determine the validity of the calculations performed in various enterprises of the competitive group using different methods of calculation. In such situation the enterprises-competitors may well make wrong management decisions what is frequently associated with ensuring of irreversible harmful consequences because of their implementation (Tsarev et al., 2008).

Another problem is the inability to obtain reliable numerical estimates of a significant number of indicators that are included in the list of growth factors for enterprises of the competitive group. Most of the analyzed indicators may be obtained only in verbal form instead of digital one. This situation is typical of the Russian reality where there is no transparency in the reporting documentation and no ways to transfer indicators from verbal form of presentation to digital. Therefore, these indicators are excluded from consideration, which negatively affects the conducted study (Tsarev et al., 2008).Empowering of the proposed methodological approach can be based on the use of methodology for multipurpose (multicriteria) optimization. Economic feasibility of these methods applying is governed by obtaining the synergetic effect as a result of implementation of the problem solution.

These of factors required changes ratio calculated to the extent of their significance can only be used for assumed forecast of the growth factors. Further research in this area can be developed only on the basis of methodology for factors evaluation at the enterprise, what is confirmed by conclusions obtained when applying methodology for qualitative analysis of labor productivity, ensuring comparability of results between separate enterprises and groups of enterprises.

\section{Conclusion}

The results of numerical simulation can be used to identify the reserves of labor productivity growth, and to develop a strategy aimed at increasing the competitiveness of industrial enterprise (toyman). Furthermore the methodology allows one to form a group of factors and evaluate their degree of influence on the labor productivity in accordance with the purpose and objectives of the study. Computer implementation of the proposed methodology makes it possible to evaluate the effectiveness and reliability of the produced solutions as a means of increasing the competitiveness (Porter).

The use of computer hardware and standard software as a tool for adaptation of approach for solving the abovementioned problem and its implementation can provide significant economic effect, repeatedly covering the expenses for research of issue on labor productivity management, and the introduction of the computer 
implementation and practical use of the proposed methodology for forming factors of labor productivity growth will improve the competitiveness of the enterprise.

Considered in the framework of the study, methodological approach to formation of indicators of labor productivity growth can become a reliable tool for developing appropriate solutions that can ensure the increase of the competitiveness of enterprises. As for the indicators, included in the model of quantitative assessment of labor productivity, one can choose not only those that reflect the resource potential, that is material and technical factors, but those that characterize management potential (for example, efficiency of equity and working capital, efficiency of investments attracted), marketing potential (for example, advertising costs, competition level, market share), distribution potential (for example, volume of sales, the number of marketing channels, stocks of finished products), financial capacity (liquidity ratios, the ratio of own funds, financial independence ratio), innovation potential (for example, volume of investment, efficiency of implementation of innovative projects), logistic potential of the enterprise. Inclusion of a large number of factors in the model will significantly expand the potential of the methodological approach.

This methodological approach can be used at the enterprises of any target market. Not only factors of productivity growth may be considered in the models, any indicator can act as the performance attribute, providing an increase of the competitiveness level in the existing market environment. In the case studies the model can be supplemented by the indicators of the competitiveness level evaluation. Although adaptation of methodology at the enterprises can be hindered by the lack of reliable publicly available information on the enterprise performance.

Further research on the elaboration of the proposed approach may be aimed at the development of approaches to the formation of groups of factors to be included in the model, expanding the range of regression dependencies, as well as the development of the universal information product, facilitating the stages of methodology.

\section{Acknowledgements}

The article was published as part of the task number 1623 to perform public works in the field of scientific activities within the frames of the state task's basic part Ministry of Education and Science of the Russian Federation.

\section{References}

Buraeva, E. (2013). The use of econometric techniques in the study of factors and reserves of labor productivity growth in the agricultural sector of economy. Ekonomichesky analiz: teoriya ipraktika, 38, 38-48.

Chizhova, E. (2010). Rationalization and innovative activities of the company and their evaluation. Belgorod: Publishing house of BSTU named after V.G. Shukhov.

Danilov, N. (2006). Course of Mathematical Economics. Moscow: Vysshaya Shkola.

Demura, N. (2013). On the estimation of the economic development of the enterprise. Sotsialno-gumanitarnye znaniya, 12, 357-364.

Firoozbakht, M. (2012). Convergence Development of Middle East Countries in Agricultural Sector. Life Science Journal, 9(1s), 7-10.

Hoskisson, R., Hitt, R. M., \& Du. Irelandand, J. H. (2012). Competing for Advantage. Cengage Learning.

Krasnopevtseva, I. (2013). Mathematical modeling of the influence of organizational factors on the level of labor productivity of industrial workers. Vestnik VSGUTU, 3(42), 80-86.

Kremer, N. (2007). The theory of probability and mathematical statistics. Moscow: UNITY.

Michael, E. P. (1998). Competitive Advantage. The Free Press.

Nikitina, E. (2014). Models and methods of management of development of industrial enterprises competitiveness. Belgorod: Publishing house of BSTU.

Novoyatlev, M. (2013). Options for predicting labor productivity using quantitative methods in construction materials industry. Vestnik Belgorodskogo gosudarstvennogo tekhnologicheskogo universitetaim, 2, $122-125$.

Podsumkova, L. (2012). Factors of labor productivity grow thin the Russian economy. Innovatsionnayadeyatelnost, 19, 43-46. 
Rahman, I., \& Idris, J. (2000). Sources of Labour Productivity Growth in Large Scale Industries. Journal Ekonomi Malaysia, 34. Retrieved from http://management6.com/Sources-of-Labour-Productivity-Growth-in-LargeScale-Industries-in-pdf-e1336.html

Roberta, S. R., \& Bernard, W. T. (2005). Operations Management: Quality and Competitiveness in a Global Environment. Wiley.

Rudychev, A., \& Novoyatlev, M. (2012). Options for predicting labor productivity using quantitative methods. Sotsialno-gumanitarnye znaniya, 8, 246-252.

Rudychev, A., Nikitina, E., \& Gavrilovskaya, S. (2013). The main aspects of preparation and development of evaluation model of enterprise competitiveness. Vestnik Belgorodskogo gosudarstvennogo tekhnologicheskogo universitetaim, 6, 137-140.

Smirnova, E. (2014). Technical equipment of enterprises is a major factor of productivity growth in the agricultural enterprises of the Ulyanovsk region. Vestnik Ulyanovskoy gosudarstvennoy selskokhozyajstvennoy akademii, 1(25), 166-171.

Sultanova, D., \& Burganov, R. (2012). Technological and managerial innovations as drivers of productivity growth. Vestnik Kazanskogo tekhnologicheskogo universiteta, 21, 203-207.

Toymentseva, I. (2012). Taking managerial decisions on the basis of economic and mathematical modeling techniques under conditions of uncertainty. Problemy ekonomiki i menedzhmenta, 11(15), 64-69.

Tsarev, V., Kantorovich, A., \& Chernysh, V. (2008). Evaluation of the competitiveness of enterprises (organizations). Theory and methodology. Moscow: UNITY-DANA.

\section{Copyrights}

Copyright for this article is retained by the author(s), with first publication rights granted to the journal.

This is an open-access article distributed under the terms and conditions of the Creative Commons Attribution license (http://creativecommons.org/licenses/by/3.0/). 